\title{
Effect of Grafted Hydroquinone on the Acid-Base Properties of Poly(acrylic acid) in the Presence of Copper (II)
}

\author{
Nabila Bensacia, ${ }^{1}$ Saâd Moulay, ${ }^{1}$ François Garin, ${ }^{2}$ Ioana Fechete, ${ }^{2}$ and Anne Boos ${ }^{3}$ \\ ${ }^{1}$ Laboratoire de Chimie-Physique Moléculaire et Macromoléculaire, Département de Chimie Industrielle, \\ Faculté des Sciences de L'Ingénieur, Université Saâd Dahlab de Blida, BP 270, route de Soumâa, 09000 Blida, Algeria \\ ${ }^{2}$ Institut de Chimie et Procédés pour l'Energie, l'Environnement et la Santé (ICPEES), UMR 7515 CNRS, Université de Strasbourg, \\ 25 rue Becquerel, 67087 Strasbourg Cedex 2, France \\ ${ }^{3}$ Institut Pluridisciplinaire Hubert Curien (IPHC), UMR 7178 CNRS, Université de Strasbourg, 25 rue Becquerel, \\ 67087 Strasbourg Cedex 2, France
}

Correspondence should be addressed to Saâd Moulay; saadmoulay@univ-blida.dz

Received 25 November 2014; Revised 1 March 2015; Accepted 9 March 2015

Academic Editor: Nurettin Sahiner

Copyright (c) 2015 Nabila Bensacia et al. This is an open access article distributed under the Creative Commons Attribution License, which permits unrestricted use, distribution, and reproduction in any medium, provided the original work is properly cited.

Potentiometric titration of poly(acrylic acid) and hydroquinone-functionalized poly(acrylic acid) was conducted in the presence of copper (II). The effects of hydroquinone functionalizing and copper (II) complexing on the potentiometric titration of poly(acrylic acid) were studied in an ionic environment and in its absence. Henderson-Hasselbalch equation was applied to assess its validity for this titration. Coordination number and the stability constants of the copper-(II-)complexed polymers were determined, and results showed the formation of mostly monodentate and bidentate copper- (II-)polymer complexes.

\section{Introduction}

Polyacrylics are a special class of polymers as far as their uses and applications are of interest. Their nowadays ubiquity stems from the large spectrum of their properties which are on a par with the chemical reactivity of their functional groups, that is, carboxylic, ester, amide, and nitrile. Polyacrylic acid (PAA), coined the name "carbopol" in pharmaceuticals, is known to be super absorbent polymer that can absorb and retain a great extent of water, a property that is exploited in hydrogels making for various controlled drug delivery systems $[1,2]$; a related fact is that the swelling behavior of PAA hydrogels was found to be highly medium $\mathrm{pH}$-dependent due to the presence of carboxylic groups [3]. Low molecular weight PAA has been valorized as an efficient salt scaling inhibitor, chiefly in oilfield operations, via the ability of the carboxylic groups in complexing metal ions [4]. A fourfold enhancement in the removal of heavy metals was observed with PAA-bound hydroquinone (HQPAA) [5]. PAA functionalized with pyridylazo-2-naphthol via reaction with carboxyl groups was employed as a fluorescent nanofiber probe for the determination of $\mathrm{Ni}^{2+}[6]$. Besides being water-soluble, PAA has a capacity to form polyelectrolyte complex nanoparticles with other polymers such as poly(ethyleneimine) [7]. Ultrathin films for electrochromic devices were made via a layer-by-layer (LBL) strategy by reacting PAA with polyaniline in an acid-base mechanism $\left(\mathrm{COOH} / \mathrm{NH}_{2}\right)$ [8]. By virtue of its carboxylic groups, PAA served as template for making helical polyaniline-PAA microwires or rods, by polymerizing aniline that is initially adsorbed on PAA matrix through electrostatic and/or hydrogen bonding interactions [9]. The plausible decarboxylation of PAA via a homolytic pathway promoted its use as a carrier of redox unit [10]. Apart from its hydrophilic character, PAA via its carboxylic groups was of a critical value in coating bleomycin-loaded magnetite nanoparticles $\left(\mathrm{Fe}_{3} \mathrm{O}_{4}\right)$ to generate an antitumoral drug delivery system [11]. As for polycarboxylic acids [12], the other facet of PAA is its propensity towards potentiometric titration and its behavior as a weak acid and a polyelectrolyte. The latter property is of a great merit because the $\mathrm{pH}$ plays a pivotal role factor in several investigations, as it indicates the real form of the involved 


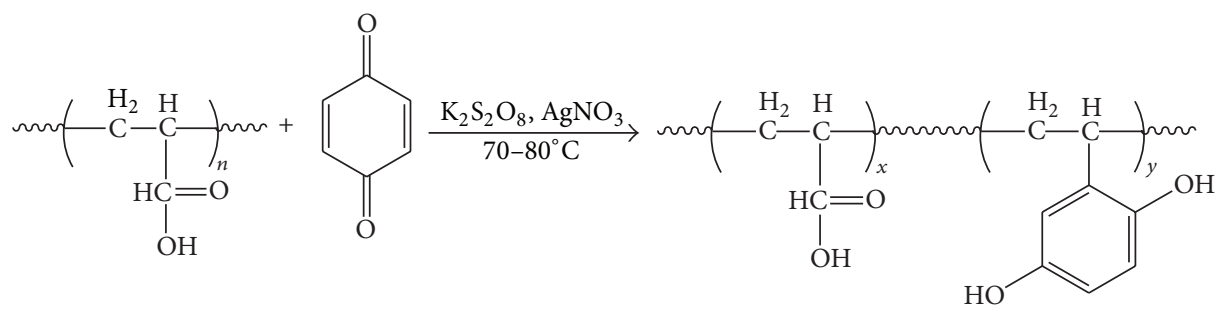

PAA

BQ

HQ-PAA

SCHEME 1

molecule (ionized and neutral species). Since 1957, numerous investigations on $\mathrm{pH}$ titration of PAA and other similar polyelectrolytes have been undertaken, elucidating several issues [13-18]. Of these issues, Gregor and Frederick [13] reported that, during potentiometric titration of PAA and polymethacrylic acid PMAA with alkali metals, binding of these metals to the polymers occurred.

In this paper, we present results on the effect of chemical functionalization with hydroquinone on potentiometric behavior of PAA in the presence of copper (II).

\section{Materials and Methods}

The chemicals were purchased from one of the following: Aldrich (France), Fluka AG, Prolabo, and Merck. Acrylic acid was purified by vacuum distillation. Azo-bis-isobutyronitrile (AIBN) was recrystallized from methanol. $p$-Benzoquinone was used as purchased. Poly(acrylic acid) synthesis and its functionalization with hydroquinone were conducted according to our previous work $[10,19]$. Molecular weights of PAA and HQ-PAA herein considered were $\left(M_{w}=2.54 \times\right.$ $\left.10^{6} \mathrm{~g} / \mathrm{mol} ; M_{n}=1.45 \times 10^{6} \mathrm{~g} / \mathrm{mol}\right)$ and $\left(M_{w}=2.38 \times\right.$ $\left.10^{6} \mathrm{~g} / \mathrm{mol} ; M_{n}=1.51 \times 10^{6} \mathrm{~g} / \mathrm{mol}\right)$, respectively.

pH-Metric Studies. Potentiometric titrations of PAA/Cu(II), (HQ) $)_{x}$ PAA/Cu(II) ( $x$, a degree of substitution equal to 0.31 ), were conducted at $20 \pm 1^{\circ} \mathrm{C}$ with a Jenway-type $\mathrm{pH}$-meter equipped with an electrode VWRI 662-1759, using $0.1 \mathrm{M}$ aqueous $\mathrm{NaOH}$ solutions; the $\mathrm{pH}$-meter was first calibrated with two standard buffer solutions $(\mathrm{pH}=4 ; \mathrm{pH}=7)$. Initial concentrations $C_{A}$ were $13.8 \times 10^{-3}$ and $8 \times 10^{-3}$ equiv/L for PAA and HQ-PAA, respectively.

\section{Results and Discussion}

Properties of polymers are obviously altered when they are functionalized. Thus, acid-base characteristics of the reported hydroquinone-functionalized PAA (HQ-PAA) [5], synthesized as shown in Scheme 1, are expected to change, particularly in the presence of heavy metals such as $\mathrm{Cu}$ (II). Potentiometric titration of PAA and PAA functionalized with $31 \%$ of hydroquinone in the presence of the latter metal ion, that is, PAA/Cu(II) and $\mathrm{HQ}-\mathrm{PAA} / \mathrm{Cu}(\mathrm{II})$, was investigated using aqueous $\mathrm{NaOH}$ as titrant. Two acidic groups exist within HQ-PAA material, the carboxylic and

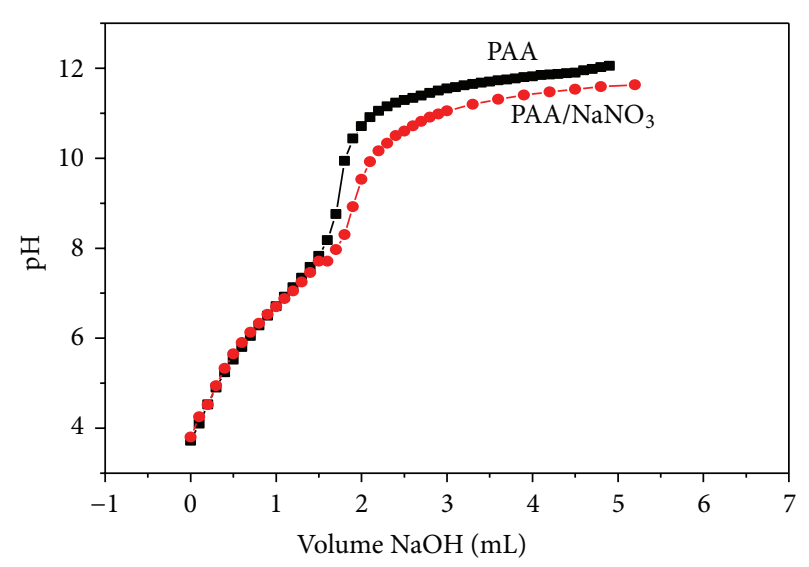

FIgUre 1: Plots of $\mathrm{pH}=\mathrm{f}\left(V_{\mathrm{NaOH}}\right)$ for PAA.

hydroquinone groups; the former is monobasic acid and the latter is dibasic one. Upon titration of PAA, polymer effect is manifested by the impact of a carboxylate group (a charged one) and the ionic environment (ionic strength), on the acidity of the adjacent carboxylic one $[14,20]$. This polymer effect would expectedly be greater for PAA/Cu(II), HQ-PAA, and $\mathrm{HQ}-\mathrm{PAA} / \mathrm{Cu}(\mathrm{II})$ as inspired from PAA-metal ion and PAA copolymer-metal ion [16-18, 21-23]. Our interest was directed towards this present study to assess the effect of $\mathrm{pH}$ on the removal of heavy metals by HQ-PAA; it was reported that metallic adsorption capacity by the PAA resin was improved when hydroquinone moiety is grafted onto the PAA matrix [5].

Figures 1 and 2 illustrate the potentiometric titration curves of PAA and PAA/Cu(II) in the absence and in the presence of an electrolyte (sodium nitrate). While Figure 1 reveals one equivalence point $\left(V_{\mathrm{NaOH}} \approx 1.875 \mathrm{~mL}, \mathrm{pH} \approx 9.2\right)$, which is in a good agreement with the reported results [24], Figure 2 displays two equivalence points $\left(V_{\mathrm{NaOH}} \approx 1.875 \mathrm{~mL}\right.$, $\left.\mathrm{pH} \approx 9.2 ; V_{\mathrm{NaOH}} \approx 0.5 \mathrm{~mL}, \mathrm{pH} \approx 4.3\right)$; the first one is attributed to the free carboxylic groups and the second to the copper-complexed one. The protons of the carboxylic groups become more acidic when they become metal-complexed. As can be seen, the effect of the ionic environment on the course of titration takes place only on the free carboxylic groups, that is beyond the equivalence point $\left(V_{\mathrm{NaOH}} \approx 1.875 \mathrm{~mL}, \mathrm{pH} \approx\right.$ 9.2); lower $\mathrm{pHs}$ were found for PAA and become higher once complexed (PAA-Cu). Thus, a clear influence of the $\mathrm{Cu}(\mathrm{II})$ 


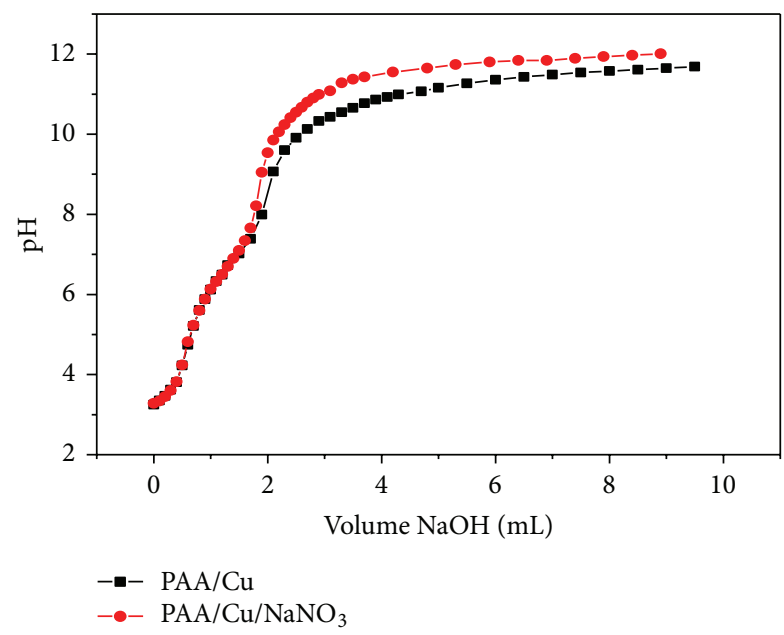

Figure 2: Plots of $\mathrm{pH}=\mathrm{f}\left(V_{\mathrm{NaOH}}\right)$ for PAA/Cu(II).

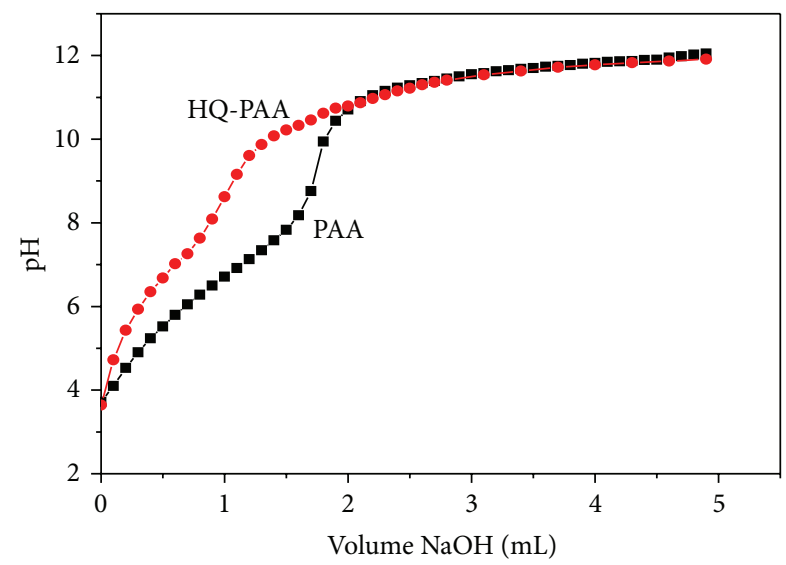

Figure 3: Plots of $\mathrm{pH}=\mathrm{f}\left(V_{\mathrm{NaOH}}\right)$ for PAA and HQ-PAA. $\left[\mathrm{NaNO}_{3}\right]$ $=0.00 \mathrm{~mol} / \mathrm{L}$.

on the acidity of the PAA is noticed. Roma-Luciow et al. [25] stated that the $\mathrm{pH}$ change may be due to the metalpolymer interactions. Noticeably, no effect of ionic environment seemed to occur at lower than this equivalence point.

The impact of functionalization of PAA with hydroquinone is evidenced in the titration profiles as pictured in Figure 3. Indeed, one equivalence point was detected in the titration curve of HQ-PAA $\left(V_{\mathrm{NaOH}} \approx 1.2 \mathrm{~mL}, \mathrm{pH} \approx\right.$ 8.78) and higher $\mathrm{pHs}$ were measured for titrant volumes up to $2 \mathrm{~mL}$. This titration point could be assigned to the free carboxylic groups, a point that is affected by the presence of hydroquinone units. Surprisingly, the two expected equivalence points inherent to the latter groups were not clearly apparent, probably when complexed with $\mathrm{Cu}(\mathrm{II})$, the titration profile (Figure 4) turned out to be similar to that of $\mathrm{Cu}$ (II)-complexed PAA (Figure 2) showing about the same equivalence points, that is $\left(V_{\mathrm{NaOH}} \approx 1.875 \mathrm{~mL}, \mathrm{pH} \approx 9.2\right.$; $V_{\mathrm{NaOH}} \approx 0.5 \mathrm{~mL}, \mathrm{pH} \approx 4.3$ ). However, the ionic environment seemed not to have an influence on the course of the titration, probably because of the presence of hydroquinone entities. Similar observations were noticed for the titration of copper-

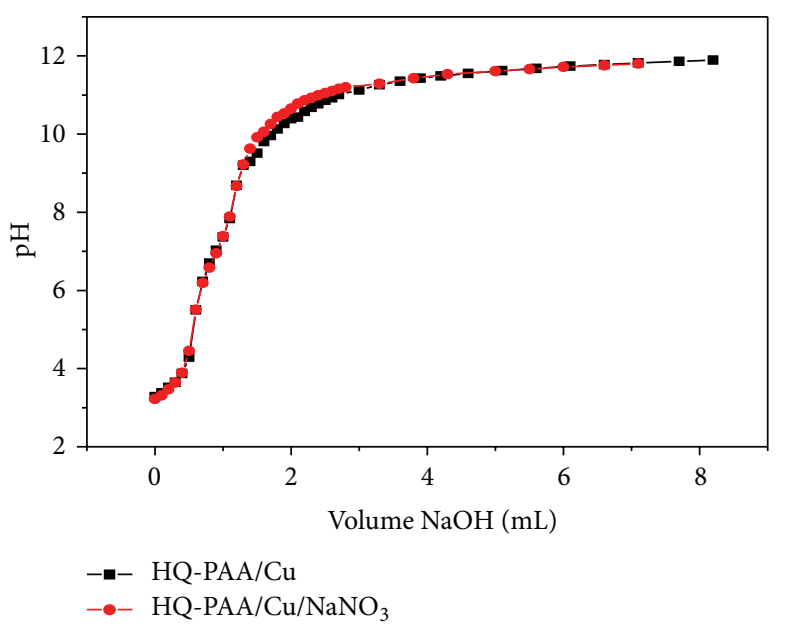

Figure 4: Plots of $\mathrm{pH}=\mathrm{f}\left(V_{\mathrm{NaOH}}\right)$ for HQ-PAA/Cu(II) and HQ$\mathrm{PAA} / \mathrm{Cu}(\mathrm{II}) / \mathrm{NaNO}_{3}$.

(II-) complexed tetrahydroxybenzene-functionalized PAA [19]. A common remark with another reported work [21] is the absence of copper hydroxide precipitate during the titration course even at higher $\mathrm{pHs}$.

Carboxylic polymers such as PAA are weak polyelectrolytes that are commonly characterized by HendersonHasselbalch equation as follows:

$$
\mathrm{pH}=\mathrm{p} K_{a}+n \log \left(\frac{\alpha}{(1-\alpha)}\right),
$$

where $\alpha$ is the dissociation coefficient, $\mathrm{p} K_{a}$ the apparent dissociation (ionization) constant (a $\mathrm{pH}$ for $\alpha=0.5$ ), and $n$ a constant quantifying the extent of the intramolecular electrostatic forces.

In the presence of metal ion, the impact of the polymermetal complexation is taken into account, and the dissociation coefficient and the apparent ionization constant of the polyelectrolyte are otherwise noted $\alpha_{M}$ and $\mathrm{p} K_{M}$ [26]. Moreover, in such a case, an average coordination number (average complexing sites) $(\widehat{r})$, a complexation constant $\left(b_{r}\right)$, and a stability constant $\beta_{12}$ were introduced to better interpret and rationalize the titration outcome and were well defined as developed by Morlay et al. [21, 22]. The average coordination number $\widehat{r}$ is correlated with $\mathrm{p}([\mathrm{HA}] / h)$ as $\log \left(C_{A} \alpha_{M}-\hat{r} C_{M}\right)=\log K_{A}{ }^{\mathrm{H}}-\mathrm{p}([\mathrm{HA}] / h), K_{A}{ }^{\mathrm{H}}$ being the apparent dissociation constant of the ligand at the considered $\mathrm{pH}$. Thus, it is often to plot $\widehat{r}$ versus $\mathrm{p}([\mathrm{HA}] / h)$, that is, $-\log ([\mathrm{HA}] / h) ;[\mathrm{HA}]$ is the concentration of the protonated polyelectrolyte and $h$ the concentration of free protons. The complexation constant $b_{r}$ is computed from $b_{r}=\left(\left[\mathrm{MA}_{r}\right] \times\right.$ $h) /\left(\left[\mathrm{MA}_{r-1}\right] \times[\mathrm{HA}]\right) ; \mathrm{M}$ and $\mathrm{A}$ stand for metal ion and polyelectrolyte, respectively, and $\left[\mathrm{MA}_{r}\right]$ and $\left[\mathrm{MA}_{r-1}\right]$ are the concentrations of the polyelectrolyte-metal complex with $r$ and $r-1$ coordination number, respectively. Practically, $b_{r}$ can be drawn from the curve of $\bar{r}=\mathrm{f}(\mathrm{p}([\mathrm{HA}] / h))$. The stability constant $\beta_{12}$ can be deduced for bidentate complex $\mathrm{MA}_{2}$ for two different $\mathrm{pHs}$ and at $\widehat{r}=0.5$ and $\widehat{r}=1.5$. 
TABLE 1: Values of $\mathrm{p} K_{M}$ and $n$ for PAA/Cu(II) and HQ-PAA/Cu(II).

\begin{tabular}{lccccc}
\hline Polymer & Molecular weight $M_{w} \times 10^{-6}(\mathrm{~g} / \mathrm{mol})$ & $C_{A} \times 10^{3}($ equiv/L) & $\mathrm{NaNO}_{3}(\mathrm{~mol} / \mathrm{L})$ & $\mathrm{p} K_{M}\left(\alpha_{M}=0.5\right)$ & \\
\hline \multirow{2}{*}{ PAA } & \multirow{2}{*}{2.54} & \multirow{2}{*}{13.8} & 0.00 & 5.49 & 1.77 \\
& & & 0.01 & $5.41[5.50]^{*}$ & $1.75[2.05]^{*}$ \\
\hline \multirow{2}{*}{ HQ-PAA } & \multirow{2}{*}{2.38} & \multirow{2}{*}{8} & 0.00 & 5.53 & 1.80 \\
& & & 0.01 & 5.48 & 1.79 \\
\hline
\end{tabular}

${ }^{*}$ Reference [21] (ionic strength of $0.1 \mathrm{~mol} / \mathrm{L}$ and molecular weight of $M_{w}=3 \times 10^{6} \mathrm{~g} / \mathrm{mol}$ ).

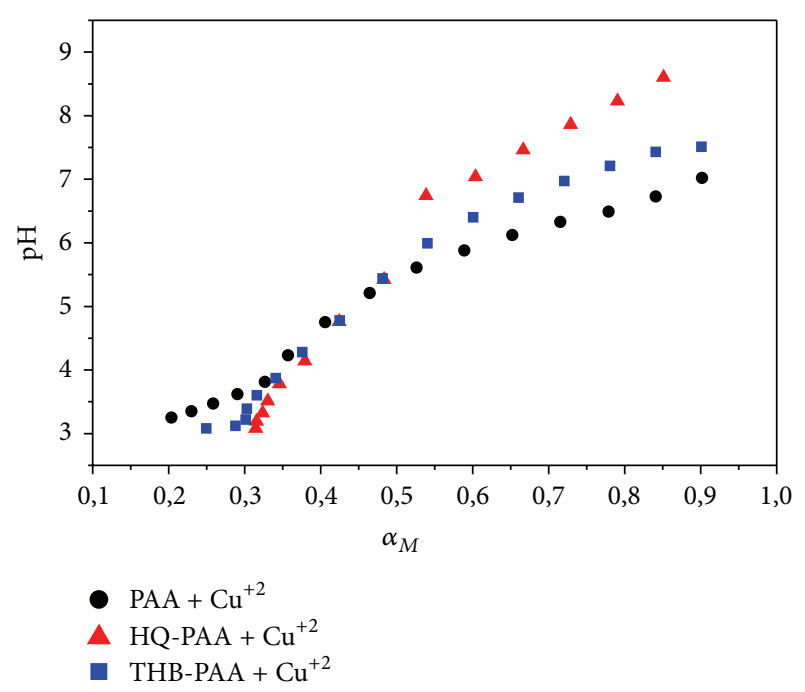

Figure 5: Plots of $\mathrm{pH}=\mathrm{f}\left(\alpha_{M}\right)$ for PAA/Cu(II) and HQ$\mathrm{PAA} / \mathrm{Cu}(\mathrm{II}) .\left[\mathrm{NaNO}_{3}\right]=0.00 \mathrm{~mol} / \mathrm{L}$. The curve in blue square is for tetrahydroxybenzene-polyacrylic acid (THB-PAA) in the presence of copper (II) [5].

Plots of $\mathrm{pH}$ against $\alpha_{M}$ for $\mathrm{Cu}(\mathrm{II})$-complexed PAA and $\mathrm{Cu}(\mathrm{II})$-complexed HQ-PAA in the absence and in the presence of electrolyte are shown in Figures 5 and 6, respectively. As shown, complexation could have occurred at $\mathrm{pH} \geq 4$; similar results were observed by Morlay et al. for PAA of a molecular weight of $3 \times 10^{6} \mathrm{~g} / \mathrm{mol}[21,22]$. From the former figure, it can be withdrawn that the hydroquinone moiety lowered the proton mobility at $\alpha_{M}$ higher than 0.4 , probably because of the plausible hydrogen bonding between carboxylic and phenolic $\mathrm{OH}$ groups. As shown in the latter figure, the gap between the profiles at these $\alpha_{M}$ values was slightly reduced, hinting at the effect of the ionic environment. Thus, the presence of $\mathrm{NaNO}_{3}$ in concentrations greater than $0.01 \mathrm{~mol} / \mathrm{L}$ would enhance appreciably the acidity of the protons of the $\mathrm{Cu}(\mathrm{II})$-complexed HQ-PAA.

Henderson-Hasselbalch equation was applied to the titration of $\mathrm{Cu}$ (II)-complexed PAA and $\mathrm{Cu}(\mathrm{II})$-complexed HQPAA with ionic strength of 0 and 0.01 (Figures 7-10). For PAA/Cu(II), this equation is valid for $\alpha_{M}$ between 0.30 and 0.6 in the absence of sodium nitrate and between 0.35 and 0.76 in its presence, corresponding roughly to a $\mathrm{pH}$ range of 4.2-6.2. For HQ-PAA/Cu(II), however, it is valid for $\alpha_{M}$ between 0.32 and 0.56 in the absence of sodium nitrate and between 0.4 and 0.6 in its presence, corresponding roughly to a $\mathrm{pH}$ range of 3.0 and 6.5 . The constants $n$ and $\mathrm{p} K_{M}$ were

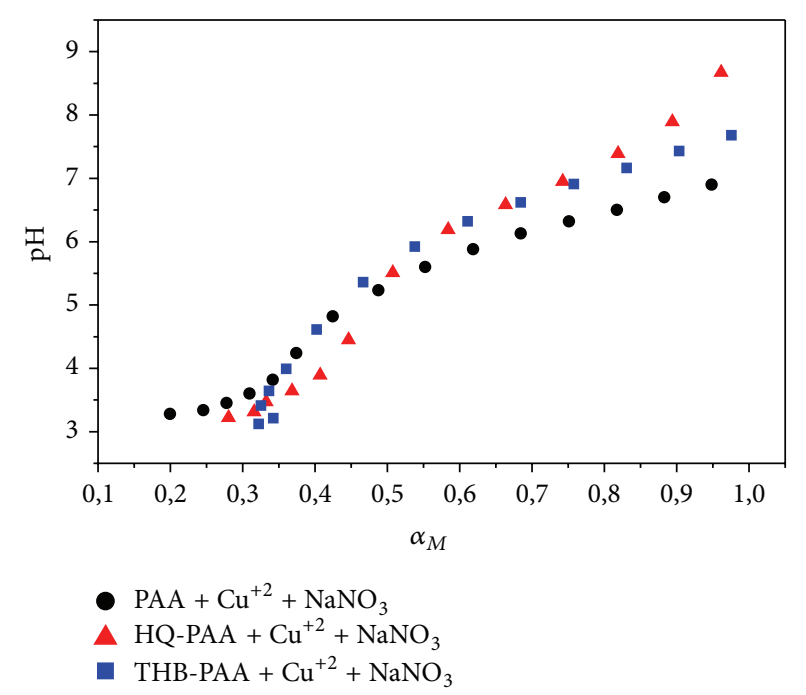

Figure 6: Plots of $\mathrm{pH}=\mathrm{f}\left(\alpha_{M}\right)$ for PAA/Cu(II) and HQ$\mathrm{PAA} / \mathrm{Cu}(\mathrm{II}) .\left[\mathrm{NaNO}_{3}\right]=0.01 \mathrm{~mol} / \mathrm{L}$. The curve in blue square is for tetrahydroxybenzene-polyacrylic acid (THB-PAA) in the presence of copper (II) and $\left[\mathrm{NaNO}_{3}\right]=0.01 \mathrm{~mol} / \mathrm{L}[5]$.

derived from these figures and their values are gathered in Table 1 . For both materials, $n$ and $\mathrm{p} K_{M}$ values were found to be nearly 1.78 and 5.50, respectively; neither the hydroquinone units nor the ionic strength did affect appreciably these constants for $\mathrm{Cu}$ (II)-complexed PAA, but insignificant lowering was noticed. Yet, a decrease of these values upon increasing the ionic strength was common observation [26, 27]. The value of $n$, an indirect measure of intramolecular electrostatic force, has been always found in the range of 2 for weak polyelectrolytes [26]; that for acetic acid is unity. Our values were lower due probably to the complexation of the polymers with copper (II). The values of $\mathrm{p} K_{M}$ were closer to those reported in the literature which fluctuated from 4.68 to 5.35 for PAA complexed with $\mathrm{Cu}(\mathrm{II}), \mathrm{Ni}(\mathrm{II}), \mathrm{Cd}(\mathrm{II})$, and $\mathrm{Pb}$ (II) [22]. It is noteworthy to recall that the acidity constant $\mathrm{p} K_{a}$ 's of acrylic acid monomer and poly(acrylic acid) were reported to be 4.20 and 6.8, respectively [28]; again, the effects of complexation and the grafted hydroquinone groups on the acid-base properties of PAA are reflected by the higher $\mathrm{p} K_{M}$ values thus obtained. The characteristic constant $\mathrm{p} K_{a}$ from Henderson-Hasselbalch equation is influenced by the neighboring groups [29].

In Figures 11 and 12 are plotted $\widehat{r}=\mathrm{f}(\mathrm{p}([\mathrm{HA}] / h))$ for $\mathrm{PAA} / \mathrm{Cu}(\mathrm{II})$ and $\mathrm{HQ}-\mathrm{PAA} / \mathrm{Cu}(\mathrm{II})$ in the presence and in the 


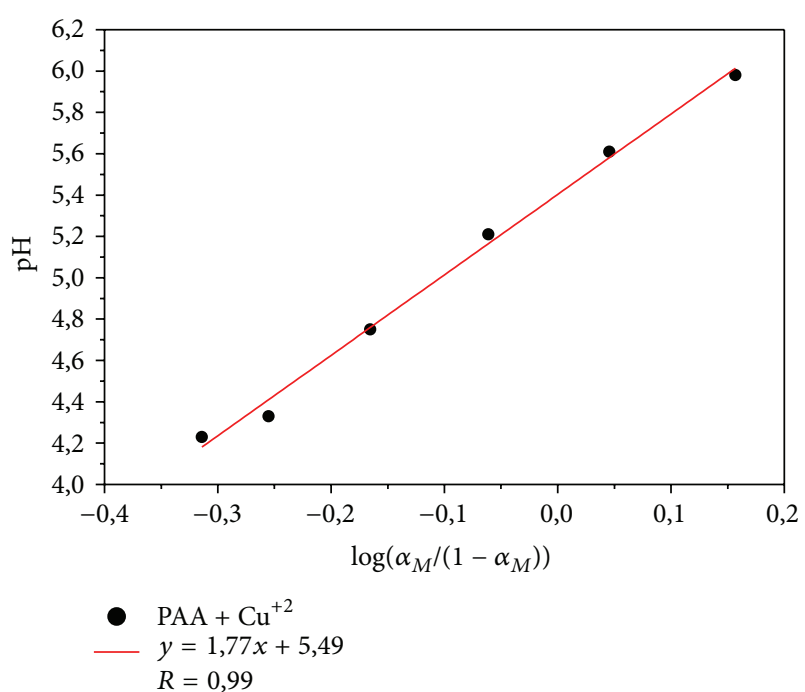

Figure 7: Plot of $\mathrm{pH}=\mathrm{f}\left(\log \left(\alpha_{M} /\left(1-\alpha_{M}\right)\right)\right)$ for PAA/Cu(II). $\left[\mathrm{NaNO}_{3}\right]=0.00 \mathrm{~mol} / \mathrm{L}$.

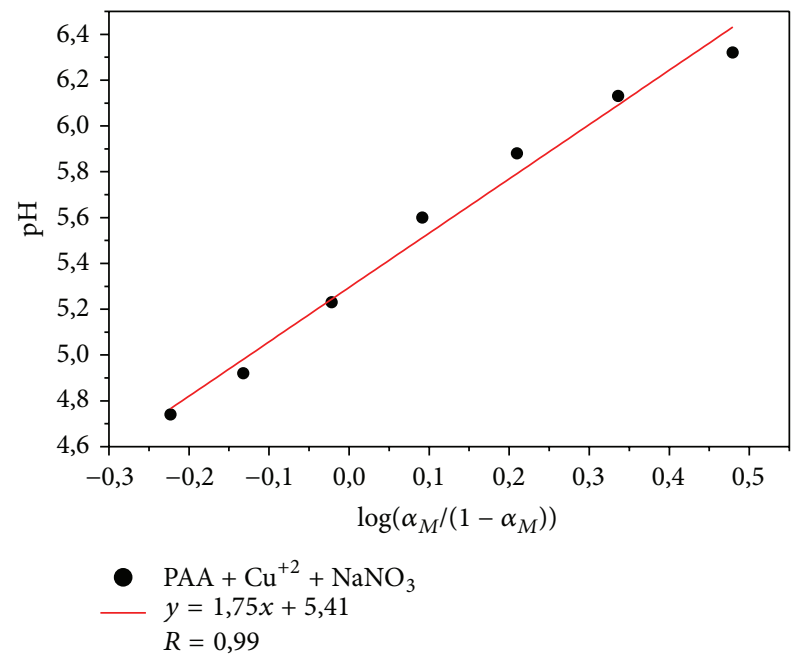

Figure 8: Plot of $\mathrm{pH}=\mathrm{f}\left(\log \left(\alpha_{M} /\left(1-\alpha_{M}\right)\right)\right)$ for PAA/Cu(II). $\left[\mathrm{NaNO}_{3}\right]=0.01 \mathrm{~mol} / \mathrm{L}$.

absence of sodium nitrate. For PAA/Cu(II), the coordination numbers increased from nearly unity to approximately 2 at $4.1<\mathrm{pH}<5.1$ (about $0.35<\alpha_{M}<0.46$ ) and leveled off to almost unity at a $\mathrm{pH}$ range of $\approx 3.15-4.1$. So, at $\mathrm{pH}$ higher than 4 , the complex $\mathrm{MA}_{2}$ was formed and at $\mathrm{pH}$ between 3 and 4 , the dominant species was $\mathrm{MA}_{1}$. The same evolution is noticed in an ionic environment of $0.01 \mathrm{~mol} / \mathrm{L}$, but higher coordination sites were formed at relatively lower $\mathrm{pHs}$; even $\mathrm{MA}_{3}$ was formed at higher $\mathrm{pHs}$ but to a small extent. For HQ$\mathrm{PAA} / \mathrm{Cu}(\mathrm{II})$, however, the average binding sites increased from 0.8 to 1.6 at $5.86<\mathrm{pH}<7.86$ (about $0.37<\alpha_{M}<0.49$ ); then a plateau at around 0.8 is seen at a $\mathrm{pH}$ range of $\approx 4.36-$ 5.86. Thus, at the first $\mathrm{pH}$ range, a mixture of $\mathrm{MA}_{1}$ and $\mathrm{MA}_{2}$ existed, and at the second $\mathrm{pH}$ range, $\mathrm{MA}_{1}$ favorably occurred. The same profile was obtained in the considered ionic environment but for relatively lower pHs.

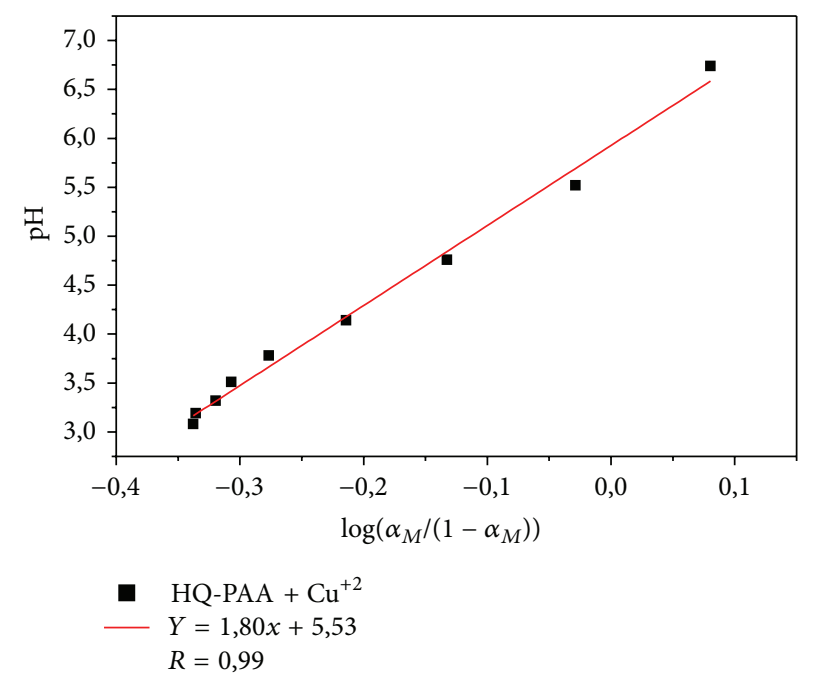

Figure 9: Plot of $\mathrm{pH}=\mathrm{f}\left(\log \left(\alpha_{M} /\left(1-\alpha_{M}\right)\right)\right)$ for HQ-PAA/Cu(II). $\left[\mathrm{NaNO}_{3}\right]=0.00 \mathrm{~mol} / \mathrm{L}$.

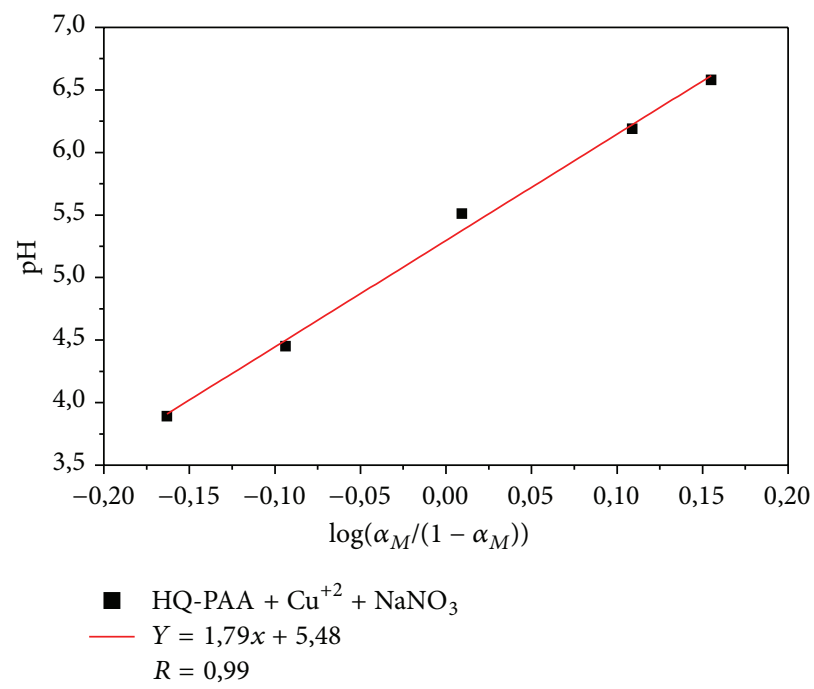

FIgURE 10: Plot of $\mathrm{pH}=\mathrm{f}\left(\log \left(\alpha_{M} /\left(1-\alpha_{M}\right)\right)\right)$ for HQ-PAA/Cu(II). $\left[\mathrm{NaNO}_{3}\right]=0.01 \mathrm{~mol} / \mathrm{L}$.

The stability constants, expressed as $\log \beta_{12}$, of $\mathrm{PAA} / \mathrm{Cu}(\mathrm{II})$ and $\mathrm{HQ}-\mathrm{PAA} / \mathrm{Cu}(\mathrm{II})$ in forms of $\mathrm{MA}_{2}$ were experimentally estimated from Figures 11 and 12 and are given in Table 2. The values of $\beta_{12}$ were $10^{10.43}$ and $10^{13.20}$ for the complexes, respectively. These great values hint at the tremendous stability of the complexes. That for the first complex is far greater than the one reported in the literature [21]. The higher value of the stability constant for the second complex would suggest the positive effect of the hydroquinone moieties on such stability, probably via chelating effect. However, ionic environment was found to suppress $\beta_{12}$ significantly for $\mathrm{HQ}-\mathrm{PAA} / \mathrm{Cu}(\mathrm{II})$ and less significantly for PAA/Cu(II). However, such large values of $\beta_{12}$ match those for Th(IV)-, Fe(III)-, and La(III)-complexed poly(maleic anhydride-co-vinyl acetate) [30]. 


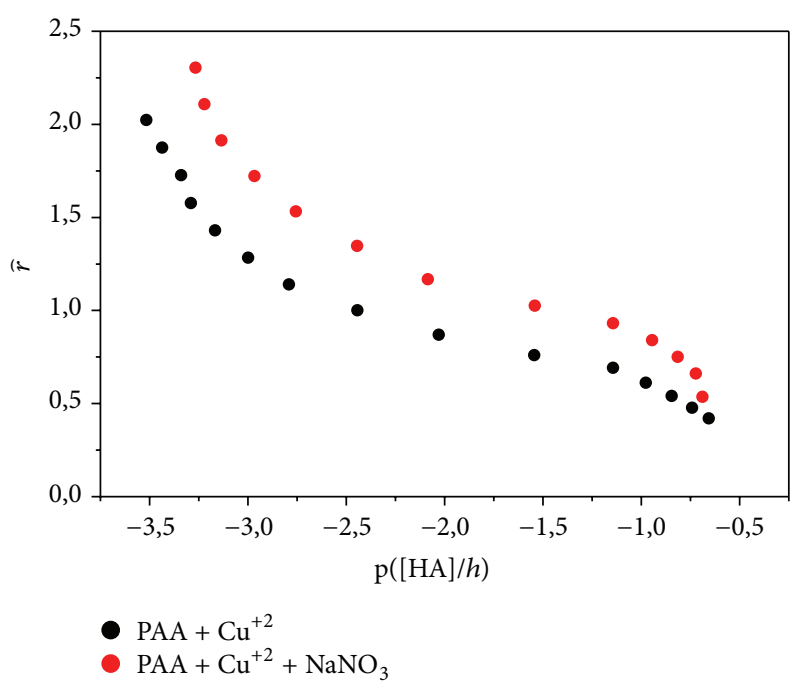

Figure 11: Plots of $\widehat{r}=\mathrm{f}(\mathrm{p}([\mathrm{HA}] / h))$ for PAA/Cu(II).

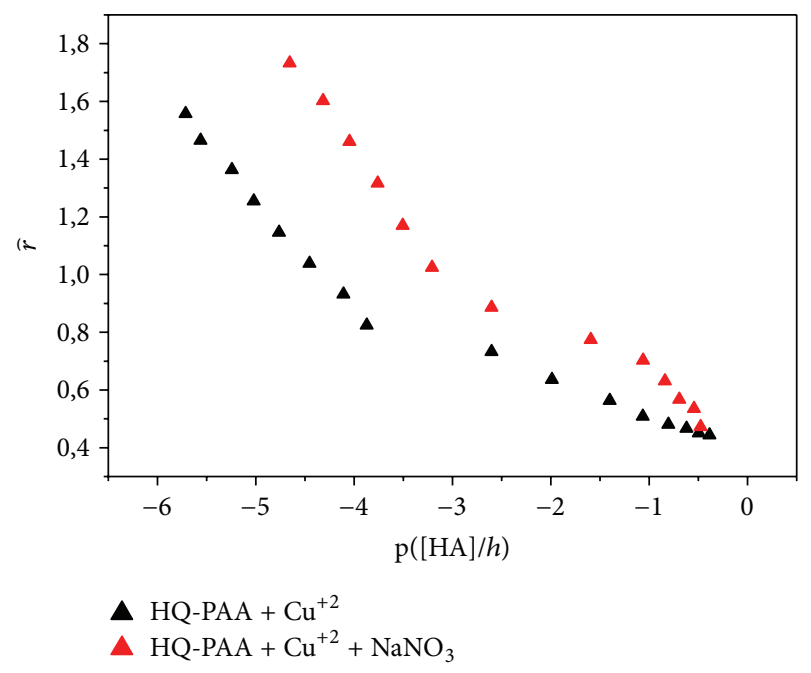

Figure 12: Plots of $\widehat{r}=\mathrm{f}(\mathrm{p}([\mathrm{HA}] / h))$ for HQ-PAA/Cu(II).

TABLE 2: Stability constants $\beta_{12}$ of copper- (II-) complexed materials.

\begin{tabular}{lcc}
\hline $\begin{array}{l}\text { Copper- (II-) complexed } \\
\text { polymer }\end{array}$ & $\begin{array}{c}{\left[\mathrm{NaNO}_{3}\right]} \\
(\mathrm{mol} / \mathrm{L})\end{array}$ & $\log \beta_{12}$ \\
\hline $\mathrm{PAA} / \mathrm{Cu}(\mathrm{II})$ & 0.00 & $10.43(6.3-6.9)^{*}$ \\
& 0.01 & 9.84 \\
\hline $\mathrm{HQ}-\mathrm{PAA} / \mathrm{Cu}(\mathrm{II})$ & 0.00 & 13.20 \\
& 0.01 & 10.86 \\
\hline
\end{tabular}

${ }^{*}$ Reference [21] (ionic strength of $0.1 \mathrm{~mol} / \mathrm{L}$ and molecular weight of $M_{w}=3$ $\left.\times 10^{6} \mathrm{~g} / \mathrm{mol}\right)$.

\section{Conclusion}

From this study, the influence of both the hydroquinone functionalizing and the copper complexing on the potentiometric titration course of poly(acrylic acid) appears clearly. The number of binding sites depended on the $\mathrm{pH}$ and the supporting electrolyte. The stability constants were, however, unexpectedly large for a divalent metal such as copper (II). This latter fact remains to be cleared up in the upcoming research.

\section{Conflict of Interests}

The authors declare that there is no conflict of interests regarding the publication of this paper.

\section{References}

[1] S. Francis, M. Kumar, and L. Varshney, "Radiation synthesis of superabsorbent poly(acrylic acid)-carrageenan hydrogels," Radiation Physics and Chemistry, vol. 69, no. 6, pp. 481-486, 2004.

[2] T. Hussain, N. M. Ranjha, and Y. Shahzad, "Swelling and controlled release of tramadol hydrochloride from a $\mathrm{pH}$-sensitive hydrogel," Designed Monomers and Polymers, vol. 14, no. 3, pp. 233-249, 2011.

[3] B. Adnadjevic and J. Jovanovic, "Novel approach in investigation of the poly(acrylic acid) hydrogel swelling kinetics in water," Journal of Applied Polymer Science, vol. 107, no. 6, pp. 3579-3587, 2008.

[4] S. Moulay, M. Boukherissa, F. Abdoune, and F. Z. Benabdelmoumene, "Low molecular weight poly(acrylic acid) as a salt scaling inhibitor in oilfield operations," Journal of the Iranian Chemical Society, vol. 2, no. 3, pp. 212-219, 2005.

[5] N. Bensacia, Fonctionalisation du polyacrylamide/acide polyacrylique par hydroquinone/tetrahydroxybenzene. Etude $\mathrm{pH}$ metrique et adsorption metallique [Ph.D. thesis], Université Saad Dahlab de Blida, Blida, Algeria, 2013.

[6] S. Adewuyi, D. A. Ondigo, R. Zugle, Z. Tshentu, T. Nyokong, and N. Torto, "A highly selective and sensitive pyridylazo-2naphthol-poly(acrylic acid) functionalized electrospun nanofiber fluorescence 'turn-off' chemosensory system for $\mathrm{Ni}^{2+}$," Analytical Methods, vol. 4, no. 6, pp. 1729-1735, 2012.

[7] M. Müller, B. Keßler, J. Fröhlich, S. Poeschla, and B. Torger, "Polyelectrolyte complex nanoparticles of poly(ethyleneimine) and poly(acrylic acid): preparation and applications," Polymers, vol. 3, no. 2, pp. 762-778, 2011.

[8] D. Li, Y. Jiang, C. Li, Z. Wu, X. Chen, and Y. Li, "Self-assembly of polyaniline/polyacrylic acid films via acid-base reaction induced deposition," Polymer, vol. 40, no. 25, pp. 7065-7070, 1999.

[9] X. Lu, Y. Yu, L. Chen et al., "Poly(acrylic acid)-guided synthesis of helical polyaniline microwires," Polymer, vol. 46, no. 14, pp. 5329-5333, 2005.

[10] S. Moulay and R. Mehdaoui, "Hydroquinone/catechol-bearing polyacrylic acid: redox polymer," Reactive and Functional Polymers, vol. 61, no. 2, pp. 265-275, 2004.

[11] Y. Xu, Y. Lin, L. Zhuang et al., "Bleomycin loaded magnetite nanoparticles functionalized by polyacrylic acid as a new antitumoral drug delivery system," BioMed Research International, vol. 2013, Article ID 462589, 5 pages, 2013.

[12] Y. Sakaguchi, J. Nishino, K. Tamaki, and T. Nagae, "Preparation and potentiometric titration of several polymer carboxylic acids," Kobunshi Kagaku, vol. 25, pp. 761-768, 1968.

[13] H. P. Gregor and M. Frederick, "Potentiometric titration of polyacrylic and polymethacrylic acids with alkali metal and quaternary ammonium bases," Journal of Polymer Science, vol. 23, no. 103, pp. 451-465, 1957. 
[14] T. N. Nekrasova, Y. V. Anufriyeva, A. M. Yel'yashevich, and O. B. Ptitsyn, "Potentiometric titration of polyacrylic acid, polymethacrylic acid and poly-l-glutamic acid," Polymer Science U.S.S.R., vol. 7, no. 5, pp. 1008-1018, 1965.

[15] M. Mandel, "The potentiometric titration of weak polyacids," European Polymer Journal, vol. 6, no. 6, pp. 807-822, 1970.

[16] T. Miyajima, M. Mori, S.-I. Ishiguro, K. H. Chung, and C. H. Moon, "On the complexation of $\mathrm{Cd}(\mathrm{II})$ ions with polyacrylic acid," Journal of Colloid and Interface Science, vol. 184, no. 1, pp. 279-288, 1996.

[17] T. Miyajima, M. Mori, and S.-I. Ishiguro, "Analysis of complexation equilibria of polyacrylic acid by a Donnan-based concept," Journal of Colloid and Interface Science, vol. 187, no. 1, pp. 259266, 1997.

[18] J. C. Benegas, R. F. M. J. Cleven, and M. A. G. T. Van den Hoop, "Potentiometric titration of poly(acrylic acid) in mixed counterion systems: chemical binding of Cd ions," Analytica Chimica Acta, vol. 369, no. 1-2, pp. 109-114, 1998.

[19] N. Bensacia and S. Moulay, "Functionalization of polyacrylic acid with tetrahydroxybenzene via a homolytic pathway: application to metallic adsorption," International Journal of Polymeric Materials, vol. 61, no. 9, pp. 699-722, 2012.

[20] M. Furukawa, R. S. Farinato, and E. Kokufuta, "Potentiometric titration behavior of poly(acrylic acid) within a cross-linked polymer network having amide groups," Colloid \& Polymer Science, vol. 286, no. 12, pp. 1425-1434, 2008.

[21] C. Morlay, M. Cromer, Y. Mouginot, and O. Vittori, "Potentiometric study of $\mathrm{Cu}$ (II) and $\mathrm{Ni}(\mathrm{II})$ complexation with two high molecular weight poly(acrylic acids)," Talanta, vol. 45, no. 6, pp. 1177-1188, 1998.

[22] C. Morlay, M. Cromer, Y. Mouginot, and O. Vittori, "Potentiometric study of $\mathrm{Cd}(\mathrm{II})$ and $\mathrm{Pb}(\mathrm{II})$ complexation with two high molecular weight poly(acrylic acids); comparison with $\mathrm{Cu}(\mathrm{II})$ and Ni(II)," Talanta, vol. 48, no. 5, pp. 1159-1166, 1999.

[23] V. V. Annenkov, E. N. Danilovtseva, V. V. Saraev, I. A. Alsarsur, and O. V. Lunionok, "Reaction of the acrylic acid and 1vinylimidazole copolymer with $\mathrm{CuCl} 2$ in aqueous solution," Russian Chemical Bulletin, vol. 50, no. 8, pp. 1382-1389, 2001.

[24] S. Bassaid, M. Chaib, A. Bouguelia, and M. Trari, "Elaboration and characterization of poly (acrylic acid-co-crotonic acid) copolymers: application to extraction of metal cations $\mathrm{Pb}$ (II), $\mathrm{Cd}(\mathrm{II})$ and $\mathrm{Hg}$ (II) by complexation in aqueous media," Reactive and Functional Polymers, vol. 68, no. 2, pp. 483-491, 2008.

[25] R. Roma-Luciow, L. Sarraf, and M. Morcellet, "Concentration effects during the formation of poly (acrylic acid)-metal complexes in aqueous solutions," Polymer Bulletin, vol. 45, no. 4-5, pp. 411-418, 2000.

[26] H. P. Gregor, "Metal-polyelectrolyte complexes. IV. Complexes of polyacrylic acid with magnesium, calcium, manganese, cobalt and zinc," Journal of Physical Chemistry, vol. 59, no. 9, pp. 990-991, 1955.

[27] J. V. McLaren, J. D. Watts, and A. Gilbert, "A study of the interaction of $\mathrm{Ni}(\mathrm{II})$ and $\mathrm{Cu}$ (II) with poly(acrylic acid)," Journal of Polymer Science Part C: Polymer Symposia, vol. 16, no. 4, pp. 1903-1915, 1967.

[28] K. Lienkamp, C. F. Kins, S. F. Alfred, A. E. Madkour, and G. N. Tew, "Water-soluble polymers from acid-functionalized norbornenes," Journal of Polymer Science, Part A: Polymer Chemistry, vol. 47, no. 5, pp. 1266-1273, 2009.

[29] A. D. Pomogailo, V. N. Kestelman, and G. I. Dzhardimalieva, "Monomeric and polymeric carboxylic acids," in Macromolecular Metal Carboxylates and Their Nanocomposites, vol. 138 of
Springer Series in Materials Science, pp. 7-25, Springer, Berlin, Germany, 2010.

[30] S. S. Mamedova, S. R. Gadzhieva, and T. G. Khanlarov, "Stability constants of polymer-metal complexes," Russian Journal of Inorganic Chemistry, vol. 53, no. 12, pp. 1964-1966, 2008. 

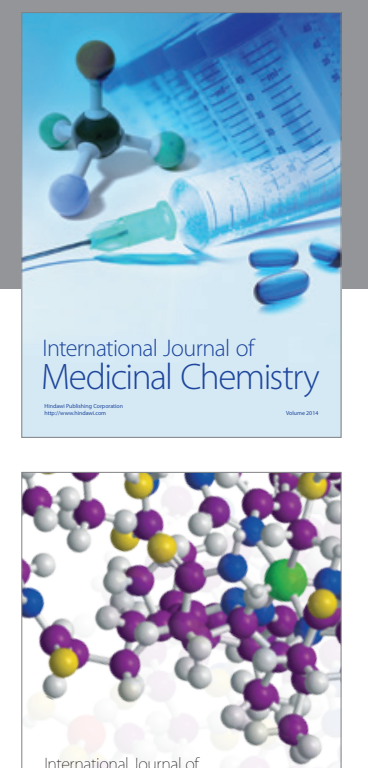

\section{Carbohydrate} Chemistry

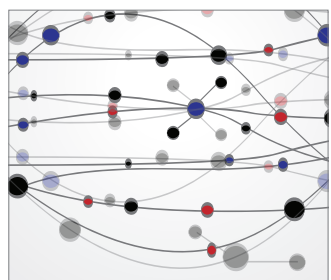

The Scientific World Journal
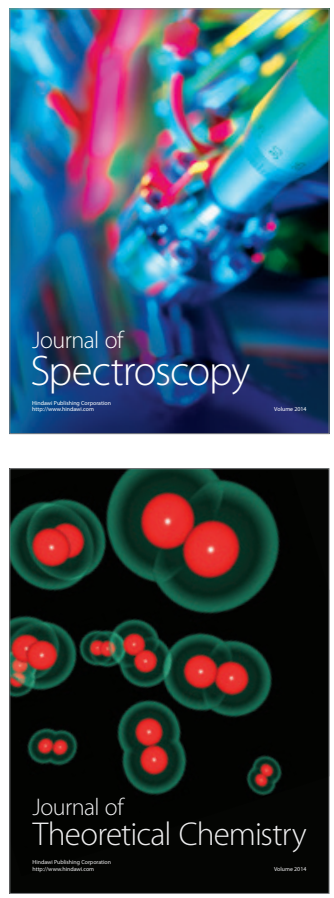
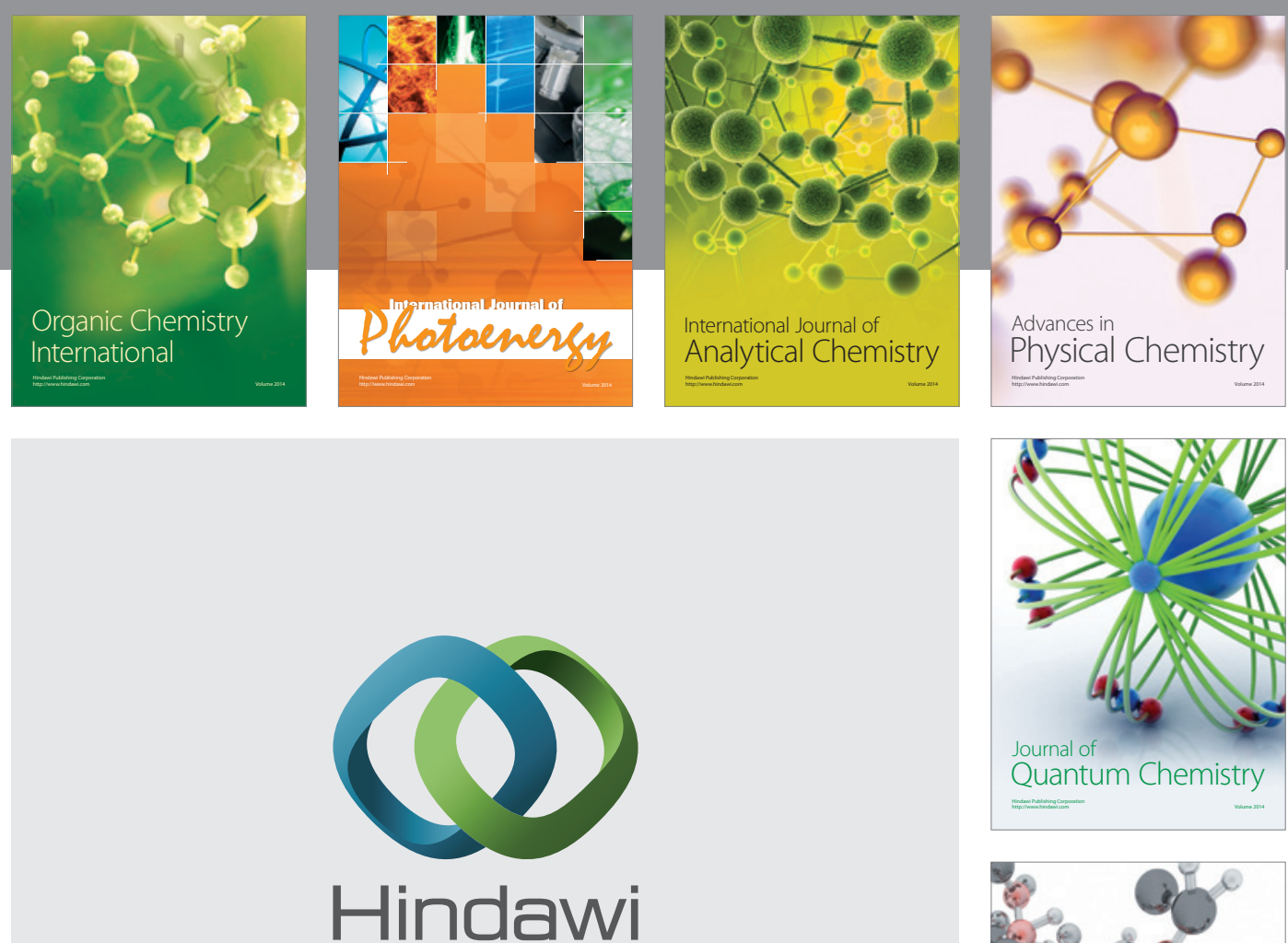

Submit your manuscripts at

http://www.hindawi.com

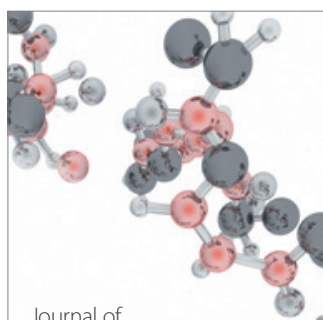

Analytical Methods

in Chemistry

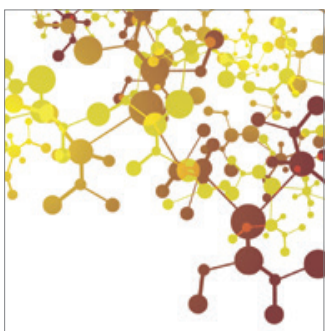

Journal of

Applied Chemistry

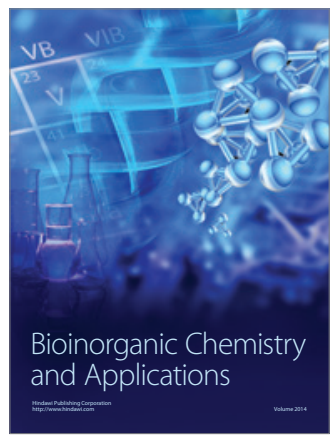

Inorganic Chemistry
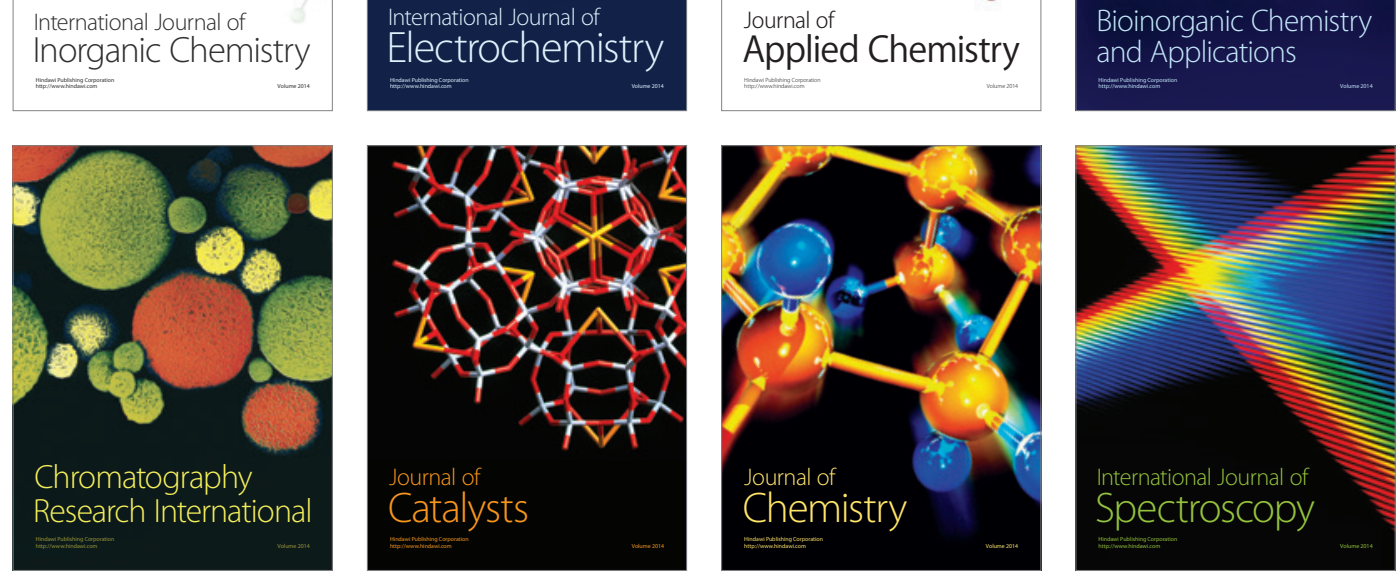